\title{
Helicobacter pylori infection is not associated with fatty liver disease including non-alcoholic fatty liver disease: a large-scale cross-sectional study in Japan
}

Kazuya Okushin ${ }^{1 \dagger}$, Yu Takahashi ${ }^{1 \dagger}$, Nobutake Yamamichi ${ }^{1 *}$, Takeshi Shimamoto ${ }^{2}$, Kenichiro Enooku', Hidetaka Fujinaga', Takeya Tsutsumi ${ }^{1}$, Yoshizumi Shintani ${ }^{1}$, Yoshiki Sakaguchi', Satoshi Ono ${ }^{1}$, Shinya Kodashima', Mitsuhiro Fujishiro' ${ }^{1}$ Kyoji Moriya ${ }^{1}$, Hiroshi Yotsuyanagi ${ }^{1}$, Toru Mitsushima ${ }^{2}$ and Kazuhiko Koike ${ }^{1}$

\begin{abstract}
Background: Fatty liver disease (FLD) including non-alcoholic fatty liver disease (NAFLD), a rapidly emerging and widely recognized liver disease today, is regarded as a hepatic manifestation of metabolic syndrome. Helicobacter pylori, one of the most common pathogens worldwide, has been reported to be associated with metabolic syndrome, but whether there is a direct association with FLD is as of yet unclear. The aim of this study was to clarify the association of FLD and NAFLD with causative background factors including Helicobacter pylori infection.

Methods: This was a cross-sectional study of Japanese adults who received medical checkups at a single medical center in 2010.Univariate and multivariate statistical analysis was performed to evaluate background factors for ultrasonography diagnosed FLD. Subjects free from alcohol influence were similarly analyzed for NAFLD.

Results: Of a total of 13,737 subjects, FLD was detected in 1,456 of 6,318 females (23.0 \%) and 3,498 of 7,419 males (47.1\%). Multivariable analyses revealed that body mass index (standardized coefficients of females and males $(\beta-F / M)=143.5 / 102.5$ ), serum ALT ( $\beta-F / M=25.8 / 75.7)$, age ( $\beta-F / M=34.3 / 17.2)$, and platelet count ( $\beta-F / M=17.8 / 15.2)$ were positively associated with FLD in both genders. Of the 5,289 subjects free from alcohol influence, NAFLD was detected in 881 of 3,473 females (25.4\%) and 921 of 1,816 males (50.7\%). Body mass index ( $\beta-F / M=113.3 / 55.3)$, serum ALT ( $\beta-F / M=21.6 / 53.8$ ), and platelet count ( $\beta-F / M=13.8 / 11.8$ ) were positively associated with NAFLD in both genders. Metabolic syndrome was positively associated with FLD and NAFLD only in males. In contrast, Helicobacter pylori infection status was neither associated with FLD nor NAFLD regardless of gender.
\end{abstract}

Conclusions: Body mass index, serum ALT and platelet count were significantly associated with FLD and NAFLD, whereas infection of Helicobacter pylori was not.

Keywords: Fatty liver disease, NAFLD, Metabolic syndrome, Helicobacter pylori

\footnotetext{
*Correspondence: nyamamic-tky@umin.ac.jp

${ }^{\dagger}$ Equal contributors

'Department of Gastroenterology, Graduate School of Medicine, The

University of Tokyo, Tokyo, Japan

Full list of author information is available at the end of the article
}

\section{Biomed Central}

(c) 2015 Okushin et al.; licensee BioMed Central. This is an Open Access article distributed under the terms of the Creative Commons Attribution License (http://creativecommons.org/licenses/by/4.0), which permits unrestricted use, distribution, and reproduction in any medium, provided the original work is properly credited. The Creative Commons Public Domain Dedication waiver (http://creativecommons.org/publicdomain/zero/1.0/) applies to the data made available in this article, unless otherwise stated. 


\section{Background}

Fatty liver disease (FLD) is the most common chronic liver disease in the world today. It is caused by multiple factors such as nutritional disorders, dyslipidemia, insulin resistance, genetic factors, etc. [1]. Especially, alcohol intake and metabolic abnormalities such as insulin resistance have been reported to be the main causes for FLD [2,3]. However, recent epidemiological studies have not been enough to elucidate complicated risk factors for FLD, despite the high prevalence and importance of the disease [4-6]. FLD is generally divided into alcoholic fatty liver disease (AFLD) and non-alcoholic fatty liver disease (NAFLD) according to amounts of alcohol intake. The boundary value of alcohol intake between AFLD and NAFLD is tentatively defined [7], but the effect of moderate alcohol intake upon FLD still leaves much room for discussion [8-10].

NAFLD is also common all over the world including Eastern countries [11], but the reported prevalence rate of NAFLD varies widely [12-17]. NAFLD is a concerning disease not only because of its high prevalence but also its potential risk of fatal diseases such as liver failure, hepatocellular carcinoma (HCC), cardiovascular disease, and so on $[18,19]$. NAFLD is regarded as a hepatic manifestation of metabolic syndrome (MS) [20]. Machado M et al. reported that the prevalence of NAFLD was $91 \%$ in obese patients who had undergone bariatric surgery [21]. It has also been reported that type 2 diabetes and other features of MS are strongly related to NAFLD $[22,23]$.

The relationship between NAFLD and microbes in the gut has been occasionally reported $[24,25]$. As "Gut-Liver Axis" has been widely noticed [26,27], several liver diseases including NAFLD are thought to be influenced by gastro-intestinal tract environments mainly decided by existing microbes. Among enormously varied microbes, to our knowledge today, Helicobacter pylori (H. pylori) shows the greatest effect on the upper gastro-intestinal environment. It is well known that approximately $50 \%$ of the global population is estimated to be infected by $H$. pylori [28], and is also well established that chronic infection of H. pylori can be a cause of chronic atrophic gastritis, peptic ulcer disease and gastric cancer [29,30]. Recently, not a few reports concerning the influence of $H$. pylori on various extra-alimentary organs have been accumulated [31-34]. Among these putative extra-alimentary disorders caused by $H$. pylori, the relation to MS is still controversial [35-42]. Though there have been many reports discussing the relationship between $H$. pylori and MS, issues to clarify still remain.

Based on these reports, we hypothesized that $H$. pylori has some associations with FLD including NAFLD. There has previously been only one similar small-scale study which concluded that $H$. pylori infection is associated with NAFLD [43]. The aim of this study was to clarify the background factors of FLD and NAFLD, and the influence of $H$. pylori infection on these diseases.

\section{Methods}

\section{Study subjects}

This was a cross-sectional study of Japanese asymptomatic adults who received medical checkups at Kameda Medical Center Makuhari (Chiba-shi, Chiba, Japan) in 2010, and voluntarily consented to entry into our study. This study was approved by the ethics committees of The University of Tokyo, and written forms of informed consent were obtained from all study participants according to the Declaration of Helsinki.

If the subject had health checkups twice in 2010, the former data was used. Criteria for exclusion were age less than 20 years, insufficient data, or poor answers to the questionnaire.

\section{Questionnaires}

A detailed questionnaire including inquiries about upper gastrointestinal tract-related symptoms [44-46], medical history, family history, lifestyle factors, etc. was filled out by all the participants. This questionnaire has already been used and validated in several previous reports [31,46-49]. Answers filled out by the participants were carefully checked by the nursing staff before being recorded into our study database. The questionnaire included five yes-no questions regarding regular intake of anticholesterol drugs, anti-hypertensive drugs, anti-diabetic drugs and corticosteroids, and history of gastrectomy. We additionally graded alcohol intake frequency on a 5-grade scale (never, rarely, sometimes, almost daily, and daily per week). In this analysis, "never" and "rarely" are regarded as non-drinker, "sometimes" is regarded as occasional-drinker, and "almost daily" and "daily" are regarded as daily-drinker. As for the amount of alcohol intake, we defined one drink unit is equivalent to a 12-ounce beer, a 4-ounce glass of wine, or a 1-ounce shot of hard liquor. And we also categorized the subjects into four groups according to: less than two units at a time, two to three units at a time, three to four units at a time and more than four units at a time. We further categorized smoking habit into three groups, current smoking (current-smoker), past habitual smoking (former-smoker), and lifelong nonsmoking (never-smoker).

\section{Diagnosis of fatty liver disease (FLD)}

Fatty liver disease (FLD) was diagnosed by abdominal ultrasonography. Routine ultrasonography evaluation of six intra-abdominal organs (liver, gallbladder, pancreas, kidneys, spleen, and abdominal aorta) was performed by well-trained operators. Characteristic findings of fatty liver are as follows; i) an increase of liver brightness, ii) an increase of hepato-renal echo contrast, iii) deep attenuation of hepatic echo, iv) existence of intra-hepatic 
vascular blurring, v) existence of focal hypoechoic lesion, and vi) existence of borderline blurring between liver and gallbladder, or right kidney. Fatty liver was diagnosed when the ultrasonographic findings satisfied both i) and ii) in addition to at least one of the findings between iii) to vi) [50]. The diagnosis was double-checked by the operators and gastroenterologists.

\section{Definition of non-alcoholic fatty liver disease (NAFLD)}

NAFLD was defined according to the guideline published from AASLD (American Association for the Study of Liver Diseases), ACG (American College of Gastroenterology), and AGA (American Gastroenterological Association) in 2012 [7]. In this present study, we defined NAFLD according to the characteristic findings as follows; i) with evidence of fatty liver by ultrasonography (see above), and ii) with no causes for secondary hepatic fat accumulation including any viral hepatitis and steatogenic medication. With regard to alcohol intake, more than 21 drink units per week in males and more than 14 drink units per week in females were widely recognized as significant alcohol intake. To exclude alcohol influence strictly, we omitted all occasional-drinkers, all daily-drinkers, and Non-drinkers who occasionally drunk more than four units at one time.

\section{Evaluation of serum anti-helicobacter pylori antibody}

Serum anti- $H$. pylori antibody was measured using a commercial EIA kit (E-plate "EIKEN" H. pylori antibody, EIKEN Chemical Co Ltd, Tokyo, Japan) as we have previously reported [48]. According to the manufacturer's instruction, an antibody titer above $10 \mathrm{U} / \mathrm{ml}$ was considered as $H$. pylori-positive. We omitted individuals who had histories of eradications of $H$. pylori from analysis.

\section{Definition of metabolic syndrome (MS)}

The definition of MS was based on the Japanese criteria published in 2005 [51]. The diagnostic criteria is visceral obesity in combination with any two of the following three standards; i) systolic blood pressure (SBP) greater than $130 \mathrm{mmHg}$ and/or diastolic blood pressure (DBP) greater than $85 \mathrm{mmHg}$, ii) triglyceride (TG) greater than $150 \mathrm{mg} / \mathrm{dL}$ and/or high-density lipoprotein (HDL) cholesterol less than $40 \mathrm{mg} / \mathrm{dL}$, iii) fasting blood sugar (FBS) greater than $110 \mathrm{mg} / \mathrm{dL}$. Visceral obesity was defined as a waist girth of at least $85 \mathrm{~cm}$ in male and at least $90 \mathrm{~cm}$ in female.

\section{Statistical analyses}

We analyzed data of female and male separately. We used JMP11 software (SAS Institute Japan) for statistical analyses. In univariate analyses, odds ratios and 95\% confidence intervals were calculated and a $p$ value of $<0.01$ was considered to indicate statistical significance. Following continuous variables were compared using the
Welch's t test or Wilcoxon's rank-sum test and following categorical variables were compared using the Fisher's exact test as appropriate for fatty liver status: age (continuous data), height (continuous data), weight (continuous data), BMI (body mass index, continuous data), AST (serum aspartate aminotransferase, continuous data), ALT (serum alanine aminotransferase, continuous data), GGT (gamma-glutamyl transpeptidase, continuous data), T-Bil (total bilirubin, continuous data), ALB (serum albumin, continuous data), PLT (platelet, continuous data), TC (total cholesterol, continuous data), HDL-C (high-density lipoprotein cholesterol, continuous data), LDL-C (low-density lipoprotein cholesterol, continuous data), TG (triglyceride, continuous data), HbA1c (continuous data), FBS (fasting blood sugar, continuous data), SBP (systolic blood pressure, continuous data), DBP (diastolic blood pressure, continuous data), Waist girth (continuous data), presence of MS (metabolic syndrome, categorical data), habit of drinking (categorical data), habit of smoking (categorical data), and H. pylori infection status (anti-H. pylori antibody, categorical data). Among the continuous variables, AST, ALT, GGT and TG were compared by Wilcoxon's rank-sum test and the other continuous variables were compared by Welch's $t$ test.

In multivariate analysis, standardized coefficient and standard error of each variable for FLD and NAFLD were calculated by the regularized logistic regression via the elastic net to avoid the correlations between each variable and a $p$ value of $<0.01$ was considered to indicate statistical significance.

\section{Results}

Participants

Of the 20,773 subjects who participated in this study, we excluded 2,119 subjects due to age less than 20 years old (2), insufficient data of several examination including ultrasonography and anti- $H$. pylori antibody $(1,814)$, or poor answers to the questionnaire $(1,141)$. The 2,119 excluded subjects had the same background characteristics as the included 18,654 subjects (Additional file 1: Table S1). Of the 18,654 subjects who met inclusion criteria (Figure 1), we further excluded 3,809 subjects who were positive for HBsAg and/or HCVAb (261), who had a history of gastrectomy (174), and who took antihypertensive drugs (2,256), anti-diabetic drugs (481), anti-cholesterol drugs $(1,515)$, or corticosteroids (186), since these factors might affect fatty liver status and/or some essential laboratory tests $[52,53]$. Finally, we further excluded 1,108 subjects who had a history of $H$. pylori eradication.

The primary study population of 13,737 subjects was comprised of 6,318 females and 7,419 males. Among them, fatty liver (FLD) was detected in 1,456 of 6,318 


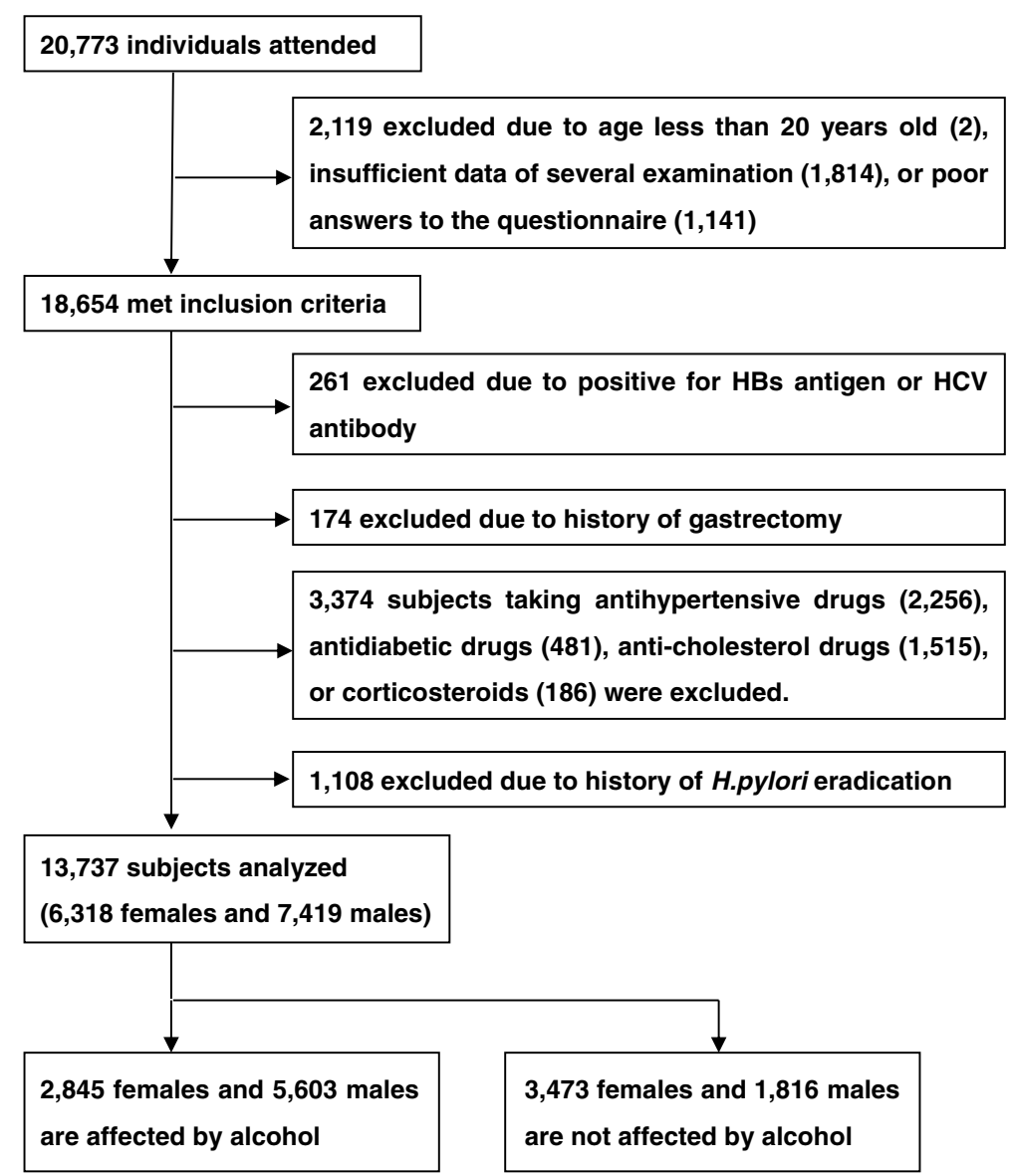

Figure 1 Of the 20,773 asymptomatic adults attended, 13,737 subjects were mainly analyzed in our present study. The subcategory of 5,289 subjects who were not affected by alcohol was also analyzed. Each figure presenting excluded patients was overlapping at the same box.

females (23.0\%) and 3,498 of 7,419 males (47.1\%). We also analyzed specific subjects who drank very little or no alcohol to remove the effects of alcohol intake to fatty liver status: after excluding all occasional-drinkers, all daily-drinkers, and non-drinkers who drank more than four units at a time, the residual 5,289 subjects $(3,473$ females and 1,816 males) were analyzed. Among them, fatty liver (i.e., NAFLD) was detected in 881 of 3,473 females (25.4\%) and 921 of 1,816 males (50.7\%).

\section{Associated factors for fatty liver disease (FLD) based on the univariate analysis}

We analyzed 19 continuous variables and 4 categorized variables and their association with fatty liver disease (Table 1, Table 2). Among the 23 examined factors, age, weight, BMI, AST, ALT, GGT, T-Bil, PLT, TC, HDL-C, LDL-C, TG, HbA1c, FBS, SBP, DBP, waist girth, presence of MS and drinking habit were statistically significant background factors in both genders. Height, ALB, smoking habit and $H$. pylori infection status were statistically significant background factors in one gender.
According to the results of univariate analyses and multicollinearity ( 0.8957 in females and 0.8723 in males between weight and BMI, 0.8521 in females and 0.7791 in males between AST and ALT), we excluded height, weight, AST and smoking habit from the next multivariate analysis. We adopted MS as a representative of waist girth, TC, HDL-C, LDL-C, TG, FBS, HbA1c, SBP and DBP. Consequently, we focused on the following nine variables for multivariate analysis: age, BMI, ALT, GGT, T-Bil, PLT, MS, drinking habit, and H. pylori infection status.

\section{Associated factors for fatty liver disease (FLD) based on the multivariate analysis}

As shown in Table 3, the generalized regression analysis demonstrated that BMI, ALT, age, and PLT were positively associated with FLD in both genders, and MS was positively associated only in males. Daily-drinking habit was negatively associated with FLD only in male. In contrast, GTT, T-Bil, and H. pylori infection status were not associated with the presence of FLD. 
Table 1 Characteristics of the 13,737 subjects (6,318 females and 7,419 males) focusing on the presence of fatty liver disease (FLD) and its association with 19 continuous variables

\begin{tabular}{|c|c|c|c|c|c|c|}
\hline \multirow[b]{2}{*}{ Variables } & \multicolumn{3}{|l|}{ Female } & \multicolumn{3}{|l|}{ Male } \\
\hline & $\begin{array}{l}\text { FLD } \\
(\mathrm{N}=1456)\end{array}$ & $\begin{array}{l}\text { non-FLD } \\
(\mathrm{N}=4862)\end{array}$ & $p$ value & $\begin{array}{l}\text { FLD } \\
(\mathrm{N}=3498)\end{array}$ & $\begin{array}{l}\text { non-FLD } \\
(N=3921)\end{array}$ & $p$ value \\
\hline Age (years old) & $50.3 \pm 7.9$ & $46.9 \pm 8.6$ & $<0.0001^{*}$ & $48.7 \pm 8.4$ & $48.1 \pm 9.5$ & $0.0012^{*}$ \\
\hline Height (cm) & $157.3 \pm 5.6$ & $158.2 \pm 5.4$ & $<0.0001^{*}$ & $170.8 \pm 5.8$ & $171.0 \pm 5.9$ & 0.0717 \\
\hline Weight (kg) & $61.8 \pm 9.6$ & $51.4 \pm 6.2$ & $<0.0001^{*}$ & $72.8 \pm 9.7$ & $64.6 \pm 7.8$ & $<0.0001^{*}$ \\
\hline BMI $\left(\mathrm{kg} / \mathrm{m}^{2}\right)$ & $25.0 \pm 3.6$ & $20.5 \pm 2.2$ & $<0.0001^{*}$ & $24.9 \pm 2.8$ & $22.1 \pm 2.2$ & $<0.0001^{*}$ \\
\hline AST (IU/I) & $21.2 \pm 8.9$ & $19.0 \pm 5.4$ & $<0.0001^{*}$ & $24.6 \pm 10.0$ & $21.3 \pm 17.1$ & $<0.0001^{*}$ \\
\hline ALT (IU/I) & $23.0 \pm 16.7$ & $16.0 \pm 7.6$ & $<0.0001^{*}$ & $33.5 \pm 22.6$ & $21.6 \pm 15.9$ & $<0.0001^{*}$ \\
\hline GGT (IU/I) & $28.3 \pm 27.8$ & $19.3 \pm 17.3$ & $<0.0001^{*}$ & $55.6 \pm 58.2$ & $38.8 \pm 38.3$ & $<0.0001^{*}$ \\
\hline T-Bil (mg/dl) & $0.71 \pm 0.27$ & $0.76 \pm 0.27$ & $<0.0001^{*}$ & $0.87 \pm 0.35$ & $0.90 \pm 0.37$ & $0.0045^{*}$ \\
\hline ALB (g/dl) & $4.26 \pm 0.21$ & $4.25 \pm 0.21$ & 0.1028 & $4.40 \pm 0.22$ & $4.36 \pm 0.22$ & $<0.0001^{*}$ \\
\hline $\operatorname{PLT}\left(10^{4} / \mu \mathrm{l}\right)$ & $26.1 \pm 5.9$ & $23.7 \pm 5.4$ & $<0.0001^{*}$ & $23.9 \pm 4.9$ & $22.9 \pm 4.7$ & $<0.0001^{*}$ \\
\hline TC (mg/dl) & $214.0 \pm 34.1$ & $198.8 \pm 33.0$ & $<0.0001^{*}$ & $207.7 \pm 32.5$ & $195.4 \pm 30.5$ & $<0.0001^{*}$ \\
\hline $\mathrm{HDL}-\mathrm{C}(\mathrm{mg} / \mathrm{dl})$ & $64.7 \pm 14.2$ & $75.8 \pm 15.4$ & $<0.0001^{*}$ & $54.1 \pm 12.7$ & $63.8 \pm 15.2$ & $<0.0001^{*}$ \\
\hline LDL-C (mg/dl) & $135.0 \pm 32.3$ & $114.2 \pm 29.9$ & $<0.0001^{*}$ & $134.8 \pm 30.2$ & $119.4 \pm 28.9$ & $<0.0001^{*}$ \\
\hline TG (mg/dl) & $107.2 \pm 80.8$ & $68.2 \pm 32.0$ & $<0.0001^{*}$ & $151.3 \pm 97.6$ & $98.7 \pm 62.6$ & $<0.0001^{*}$ \\
\hline HbA1c (\%) & $5.52 \pm 0.56$ & $5.30 \pm 0.33$ & $<0.0001^{*}$ & $5.50 \pm 0.62$ & $5.29 \pm 0.37$ & $<0.0001^{*}$ \\
\hline FBS (mg/dl) & $94.9 \pm 15.2$ & $88.3 \pm 8.5$ & $<0.0001^{*}$ & $100.1 \pm 16.4$ & $94.1 \pm 10.0$ & $<0.0001^{*}$ \\
\hline SBP $(\mathrm{mmHg})$ & $118.8 \pm 16.5$ & $107.7 \pm 14.5$ & $<0.0001^{*}$ & $121.4 \pm 15.0$ & $115.4 \pm 14.7$ & $<0.0001^{*}$ \\
\hline $\mathrm{DBP}(\mathrm{mmHg})$ & $73.9 \pm 10.5$ & $67.2 \pm 9.6$ & $<0.0001^{*}$ & $77.0 \pm 10.1$ & $73.0 \pm 9.8$ & $<0.0001^{*}$ \\
\hline Waist (cm) & $87.2 \pm 8.6$ & $75.7 \pm 6.5$ & $<0.0001^{*}$ & $87.4 \pm 7.1$ & $79.8 \pm 6.4$ & $<0.0001^{*}$ \\
\hline
\end{tabular}

$F L D$ : fatty liver disease. Data show mean $\pm S D$ (standard deviation) of each variable. By applying the Welch's $t$ test or Wilcoxon analysis, $p$ values were calculated. The level of significance was set below $0.01(*)$.

Table 2 Characteristics of the 13,737 subjects (6,318 females and 7,419 males) focusing on the presence of fatty liver disease (FLD) and its association with four categorized variables

\begin{tabular}{|c|c|c|c|c|c|c|}
\hline \multirow[b]{2}{*}{ Variables } & \multicolumn{3}{|l|}{ Female } & \multicolumn{3}{|l|}{ Male } \\
\hline & $\begin{array}{l}\text { FLD } \\
(N=1456)\end{array}$ & $\begin{array}{l}\text { non-FLD } \\
(\mathrm{N}=4862)\end{array}$ & $p$ value & $\begin{array}{l}\text { FLD } \\
(\mathrm{N}=3498)\end{array}$ & $\begin{array}{l}\text { non-FLD } \\
(N=3921)\end{array}$ & $p$ value \\
\hline MS & & & $<0.0001^{*}$ & & & $<0.0001^{*}$ \\
\hline Non-MS & 1391 (22.3 \%) & 4860 (77.6 \%) & & 2945 (43.5 \%) & 3832 (56.5 \%) & \\
\hline MS & 65 (97.0 \%) & 2 (3.0\%) & & 553 (86.1 \%) & 89 (13.9 \%) & \\
\hline Alcohol & & & $<0.0001^{*}$ & & & $<0.0001^{*}$ \\
\hline Non-drinker & 884 (25.3 \%) & 2604 (74.7 \%) & & 951 (50.8 \%) & 923 (49.3 \%) & \\
\hline $\begin{array}{l}\text { Occasional- } \\
\text { drinking }\end{array}$ & 368 (20.2 \%) & 1456 (79.8 \%) & & 1114 (49.9\%) & 1120 (50.1\%) & \\
\hline Daily-drinker & 204 (20.3 \%) & 802 (79.7 \%) & & 1433 (43.3 \%) & 1878 (56.7 \%) & \\
\hline Smoking & & & 0.0467 & & & $0.0045^{*}$ \\
\hline Current-smoker & $123(27.8 \%)$ & 319 (72.2 \%) & & 1116 (49.3\%) & 1147 (50.7 \%) & \\
\hline Former-smoker & 174 (23.2 \%) & 577 (76.8 \%) & & 1317 (47.6 \%) & 1450 (52.4 \%) & \\
\hline Never-smoker & 1159 (22.6 \%) & 3966 (77.4 \%) & & 1065 (44.6 \%) & 1324 (55.4 \%) & \\
\hline H. pylori Ab & & & $<0.0001^{*}$ & & & 0.6446 \\
\hline Negative & 1003 (21.5 \%) & 3665 (78.5 \%) & & 2474 (47.0 \%) & 2793 (53.0 \%) & \\
\hline Positive & $453(27.5 \%)$ & 1197 (72.6 \%) & & 1024 (47.6 \%) & 1128 (52.4\%) & \\
\hline
\end{tabular}


Table 3 Multivariate analyses evaluating association between the presence of fatty liver disease (FLD) and 9 selected variables among the 13,737 subjects $(6,318$ females and 7,419 males $)$.

\begin{tabular}{|c|c|c|c|c|c|c|}
\hline \multirow[b]{2}{*}{ Variables } & \multicolumn{3}{|l|}{ Female } & \multicolumn{3}{|l|}{ Male } \\
\hline & $\begin{array}{l}\text { Standardized } \\
\text { coefficient }\end{array}$ & $\begin{array}{l}\text { Standard } \\
\text { error }\end{array}$ & $p$ value & $\begin{array}{l}\text { Standardized } \\
\text { coefficient }\end{array}$ & $\begin{array}{l}\text { Standard } \\
\text { error }\end{array}$ & $p$ value \\
\hline $\mathrm{BMI}$ & 143.5 & 4.8 & $<0.0001^{*}$ & 102.5 & 3.7 & $<0.0001^{*}$ \\
\hline ALT & 25.8 & 5.1 & $<0.0001^{*}$ & 75.7 & 13.1 & $<0.0001^{*}$ \\
\hline Age & 34.3 & 3.5 & $<0.0001^{*}$ & 17.2 & 2.8 & $<0.0001^{*}$ \\
\hline PLT & 17.8 & 3.1 & $<0.0001^{*}$ & 15.2 & 2.6 & $<0.0001^{*}$ \\
\hline \multicolumn{7}{|l|}{ Alcohol } \\
\hline $\begin{array}{l}\text { Occasional- } \\
\text { drinker }\end{array}$ & -8.1 & 3.7 & 0.0270 & -5.9 & 2.8 & 0.0371 \\
\hline Daily-drinker & 8.5 & 3.7 & 0.0209 & -8.4 & 2.9 & $0.0040^{*}$ \\
\hline \multicolumn{7}{|l|}{ MS } \\
\hline Positive & 10.2 & 5.9 & 0.0804 & 16.4 & 3.2 & $<0.0001^{*}$ \\
\hline GGT & 5.3 & 3.1 & 0.0919 & 4.0 & 4.1 & 0.3399 \\
\hline T-Bil & -3.1 & 3.3 & 0.3386 & 1.4 & 2.4 & 0.5555 \\
\hline \multicolumn{7}{|l|}{ H. pylori } \\
\hline Positive & 1.0 & 3.1 & 0.7558 & -2.8 & 2.5 & 0.2642 \\
\hline
\end{tabular}

MS: metabolic syndrome, C.I.: confidence interval, $A b$ : antibody, Using the logistic regression analysis, $p$ values were calculated. The level of significance was set

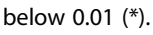

\section{Associated factors for non-alcoholic fatty liver disease (NAFLD) based on the univariate analysis}

Furthermore, we analyzed the 5,289 subjects free from alcohol influence to evaluate the relationship between NAFLD and background factors including $H$. pylori infection status. We analyzed 19 continuous variables and 3 categorized variables and their association with fatty liver disease (Tables 4 and 5). Among the 22 examined factors, weight, BMI, AST, ALT, GGT, PLT, TC, HDL-C, TG, HbA1c, FBS, SBP, DBP, waist girth, and MS were statistically significant in both genders. Age, height, T-Bil, ALB, and smoking habit were statistically significant in only one gender. However, regardless of gender, $H$. pylori infection status was not associated with the presence of NAFLD.

According to the results of univariate analyses and multicollinearity (0.9024 in female and 0.8841 in male between weight and BMI, 0.8626 in female and 0.8440 in male between AST and ALT), we excluded height, weight, AST, T-Bil, and smoking habit from the next multivariate analysis. We adopted MS as a representative of waist girth, TC, HDL-C, LDL-C, TG, FBS, HbA1c, SBP and DBP. Consequently, we chose the following seven variables for multivariate analysis: Age, BMI, ALT, GGT, PLT, MS, and H. pylori infection status.

\section{Associated factors for non-alcoholic fatty liver disease (NAFLD) based on the multivariate analysis}

As shown in Table 6, the generalized regression analysis displayed that BMI, ALT, and PLT were positively associated with the presence of NAFLD. Age was positively associated with NAFLD only in females, whereas MS was positively associated only in males. Like FLD, $H$. pylori infection status did not show significant association with NAFLD, regardless of gender.

\section{Discussion}

\section{Background factors for FLD}

As for FLD, BMI, ALT, age and PLT were positively associated with the presence of FLD in both genders, which is concurrent with the recent study report from Japan [54].

Although alcohol intake has been regarded as a main cause for fatty liver for a long time [1,55-58], our result did not demonstrate a significant positive association between the frequency of alcohol intake and the presence of fatty liver. Occasional alcohol intake tended to be negatively associated with fatty liver in both genders, similarly to a recent report [8]. (Table 3). There is a possibility that the negative association of alcohol intake to FLD in daily-drinking males is attributed to the design of this study, since the evaluation of amounts of alcohol intake was not quantitatively accurate. To validate our result; the association between alcohol and fatty liver may not be as significant as previously reported, more detailed information of alcohol intake and careful setup of the study cohort will be needed in future studies.

\section{Background factors for NAFLD}

As for NAFLD, BMI, ALT, and PLT showed positive association. Unlike FLD, age was positively associated with the presence of NAFLD only in females (Table 6). Female gender, age, diabetes mellitus, hyperinsulinaemia, obesity 
Table 4 Characteristics of the alcohol-free 5,289 subjects (3,473 females and 1,816 males) focusing on the presence of fatty liver (NAFLD) and its association with 19 continuous variables

\begin{tabular}{|c|c|c|c|c|c|c|}
\hline \multirow[b]{2}{*}{ Variables } & \multicolumn{3}{|l|}{ Female } & \multicolumn{3}{|l|}{ Male } \\
\hline & $\begin{array}{l}\text { NAFLD } \\
(\mathrm{N}=881)\end{array}$ & $\begin{array}{l}\text { non-NAFLD } \\
(\mathrm{N}=2592)\end{array}$ & $p$ value & $\begin{array}{l}\text { NAFLD } \\
(\mathrm{N}=921)\end{array}$ & $\begin{array}{l}\text { non-NAFLD } \\
(\mathrm{N}=895)\end{array}$ & $p$ value \\
\hline Age (years old) & $50.8 \pm 8.1$ & $47.6 \pm 8.9$ & $<0.0001^{*}$ & $47.6 \pm 8.6$ & $47.4 \pm 10.1$ & 0.5126 \\
\hline Height (cm) & $156.9 \pm 5.4$ & $157.8 \pm 5.5$ & $<0.0001^{*}$ & $170.7 \pm 5.8$ & $170.9 \pm 6.0$ & 0.4956 \\
\hline Weight (kg) & $61.8 \pm 9.8$ & $51.2 \pm 6.3$ & $<0.0001^{*}$ & $72.8 \pm 10.0$ & $63.8 \pm 8.0$ & $<0.0001^{*}$ \\
\hline BMI $\left(\mathrm{kg} / \mathrm{m}^{2}\right)$ & $25.1 \pm 3.7$ & $20.5 \pm 2.3$ & $<0.0001^{*}$ & $25.0 \pm 3.0$ & $21.8 \pm 2.3$ & $<0.0001^{*}$ \\
\hline AST (IU/I) & $21.4 \pm 9.2$ & $19.0 \pm 5.4$ & $<0.0001^{*}$ & $23.8 \pm 10.6$ & $20.0 \pm 5.3$ & $<0.0001^{*}$ \\
\hline ALT (IU/I) & $23.5 \pm 17.7$ & $16.2 \pm 7.8$ & $<0.0001^{*}$ & $35.1 \pm 30.7$ & $21.3 \pm 9.4$ & $<0.0001^{*}$ \\
\hline GGT (IU/I) & $26.4 \pm 24.6$ & $18.2 \pm 14.8$ & $<0.0001^{*}$ & $40.5 \pm 41.0$ & $26.6 \pm 22.4$ & $<0.0001^{*}$ \\
\hline T-Bil (mg/dl) & $0.71 \pm 0.26$ & $0.74 \pm 0.26$ & $<0.0004^{*}$ & $0.85 \pm 0.36$ & $0.86 \pm 0.37$ & 0.5524 \\
\hline ALB (g/dl) & $4.26 \pm 0.22$ & $4.24 \pm 0.21$ & 0.0148 & $4.41 \pm 0.23$ & $4.35 \pm 0.22$ & $<0.0001^{*}$ \\
\hline $\operatorname{PLT}\left(10^{4} / \mu \mathrm{l}\right)$ & $26.1 \pm 6.0$ & $23.7 \pm 5.6$ & $<0.0001^{*}$ & $24.7 \pm 5.1$ & $22.9 \pm 4.9$ & $<0.0001^{*}$ \\
\hline TC (mg/dl) & $213.2 \pm 33.4$ & $201.2 \pm 33.6$ & $<0.0001^{*}$ & $207.4 \pm 32.9$ & $192.6 \pm 29.9$ & $<0.0001^{*}$ \\
\hline $\mathrm{HDL}-\mathrm{C}(\mathrm{mg} / \mathrm{dl})$ & $62.9 \pm 14.0$ & $74.1 \pm 15.0$ & $<0.0001^{*}$ & $50.5 \pm 10.7$ & $59.5 \pm 13.8$ & $<0.0001^{*}$ \\
\hline LDL-C (mg/dl) & $136.0 \pm 31.8$ & $118.2 \pm 30.3$ & $<0.0001^{*}$ & $138.6 \pm 29.5$ & $121.3 \pm 27.8$ & $<0.0001^{*}$ \\
\hline TG (mg/dl) & $107.8 \pm 71.0$ & $69.1 \pm 31.2$ & $<0.0001^{*}$ & $144.1 \pm 92.0$ & $91.6 \pm 47.7$ & $<0.0001^{*}$ \\
\hline HbA1c (\%) & $5.55 \pm 0.54$ & $5.34 \pm 0.35$ & $<0.0001^{*}$ & $5.51 \pm 0.63$ & $5.31 \pm 0.40$ & $<0.0001^{*}$ \\
\hline FBS (mg/dl) & $94.5 \pm 14.7$ & $88.1 \pm 9.1$ & $<0.0001^{*}$ & $98.4 \pm 17.0$ & $92.2 \pm 8.5$ & $<0.0001^{*}$ \\
\hline SBP $(\mathrm{mmHg})$ & $119.4 \pm 16.8$ & $107.7 \pm 14.4$ & $<0.0001^{*}$ & $118.6 \pm 14.5$ & $111.2 \pm 13.3$ & $<0.0001^{*}$ \\
\hline $\mathrm{DBP}(\mathrm{mmHg})$ & $74.2 \pm 10.6$ & $66.9 \pm 9.5$ & $<0.0001^{*}$ & $74.9 \pm 9.4$ & $70.0 \pm 8.8$ & $<0.0001^{*}$ \\
\hline Waist (cm) & $87.3 \pm 8.7$ & $75.7 \pm 6.5$ & $<0.0001^{*}$ & $87.3 \pm 7.5$ & $78.6 \pm 6.6$ & $<0.0001^{*}$ \\
\hline
\end{tabular}

NAFLD: non-alcoholic fatty liver disease. Data show mean $\pm S D$ (standard deviation) of each variable. By applying the Welch's $t$ test or Wilcoxon analysis, $p$ values were calculated. The level of significance was set below $0.01(*)$.

and hypertriglyceridaemia have been regarded as traditional risk factors for NAFLD [3,59-61]. Our results denoted the same tendency of these previous reports, but MS wasn't associated with the presence of NAFLD in females.
Association between $\mathrm{H}$. pylori and FLD including NAFLD Concerning $H$. pylori infection, neither FLD nor NAFLD displayed a significant association in multivariate analysis regardless of gender, though $H$. pylori infection showed significant association in univariate analysis in

Table 5 Characteristics of the alcohol-free 5,289 subjects (3,473 females and 1,816 males) focusing on the presence of fatty liver (NAFLD) and its association with three categorized variables

\begin{tabular}{|c|c|c|c|c|c|c|}
\hline \multirow[b]{2}{*}{ Variables } & \multicolumn{3}{|l|}{ Female } & \multicolumn{3}{|l|}{ Male } \\
\hline & $\begin{array}{l}\text { NAFLD } \\
(\mathrm{N}=881)\end{array}$ & $\begin{array}{l}\text { non-NAFLD } \\
(\mathrm{N}=2592)\end{array}$ & $p$ value & $\begin{array}{l}\text { NAFLD } \\
(\mathrm{N}=921)\end{array}$ & $\begin{array}{l}\text { non-NAFLD } \\
(\mathrm{N}=895)\end{array}$ & $p$ value \\
\hline MS & & & $<0.0001^{*}$ & & & $<0.0001^{*}$ \\
\hline Non-MS & $838(24.5 \%)$ & 2590 (75.6 \%) & & $793(47.2 \%)$ & 886 (52.8 \%) & \\
\hline MS & 43 (95.6\%) & $2(4.4 \%)$ & & $128(93.4 \%)$ & $9(6.6 \%)$ & \\
\hline Smoking & & & 0.3913 & & & $0.0033^{*}$ \\
\hline Current-smoker & 54 (29.4 \%) & 130 (70.7 \%) & & $289(54.4 \%)$ & 242 (45.6 \%) & \\
\hline Former-smoker & $71(24.0 \%)$ & 225 (76.0 \%) & & 284 (53.7\%) & 245 (46.3 \%) & \\
\hline Never-smoker & 756 (25.3 \%) & 2237 (74.7 \%) & & $348(46.0 \%)$ & 408 (54.0 \%) & \\
\hline H. pylori Ab & & & 0.0145 & & & 0.8742 \\
\hline Negative & $610(24.2 \%)$ & 1907 (75.8%) & & $669(50.6 \%)$ & 654 (49.4 \%) & \\
\hline Positive & $271(28.4 \%)$ & 685 (71.7 \%) & & $252(51.1 \%)$ & 241 (48.9 \%) & \\
\hline
\end{tabular}

NAFLD: non-alcoholic fatty liver disease, MS: metabolic syndrome, Ab: antibody. By applying the Fisher's exact test, $p$ values were calculated. The level of significance was set below $0.01\left(^{*}\right)$. 
Table 6 Multivariate analysis evaluating association between NAFLD and 7 selected variables among the non-drinking 5,289 subjects $(3,473$ females and 1,816 males $)$

\begin{tabular}{|c|c|c|c|c|c|c|}
\hline \multirow[b]{2}{*}{ Variables } & \multicolumn{3}{|l|}{ Female } & \multicolumn{3}{|l|}{ Male } \\
\hline & $\begin{array}{l}\text { Standardized } \\
\text { Coefficient }\end{array}$ & $\begin{array}{l}\text { Standard } \\
\text { error }\end{array}$ & $p$ value & $\begin{array}{l}\text { Standardized } \\
\text { Coefficient }\end{array}$ & $\begin{array}{l}\text { Standard } \\
\text { error }\end{array}$ & $p$ value \\
\hline $\mathrm{BMI}$ & 113.3 & 4.9 & $<0.0001^{*}$ & 55.3 & 3.7 & $<0.0001^{*}$ \\
\hline ALT & 21.6 & 6.1 & $0.0004^{*}$ & 53.8 & 6.5 & $<0.0001^{*}$ \\
\hline Age & 25.0 & 3.5 & $<0.0001^{*}$ & 3.7 & 2.6 & 0.1607 \\
\hline PLT & 13.8 & 3.0 & $<0.0001^{*}$ & 11.8 & 2.5 & $<0.0001^{*}$ \\
\hline \multicolumn{7}{|l|}{ MS } \\
\hline Positive & 5.9 & 5.0 & 0.2354 & 11.6 & 4.5 & $0.0092^{*}$ \\
\hline GGT & 2.3 & 3.4 & 0.4975 & 0.24 & 3.9 & 0.9508 \\
\hline \multicolumn{7}{|l|}{ H. pylori } \\
\hline Positive & -1.2 & 3.1 & 0.7017 & -1.8 & 2.6 & 0.4764 \\
\hline
\end{tabular}

MS: metabolic syndrome, $A b$ : antibody, C.I.: confidence interval. Using the logistic regression analysis, $p$ values were calculated. The level of significance was set below $\left.0.01{ }^{*}\right)$.

FLD in female. This suggests that upper gastro-intestinal environment caused by chronic $H$. pylori infection has no or marginal influence on the development of fatty liver. These results are consistent with some previous reports $[35,36]$.

\section{Limitations and future prospects}

The first limitation of our study is the study design itself (i.e., cross-sectional study). A single point analysis cannot obtain accurate results, since fatty liver is thought to emerge as a consequence of several risk factors over a number of years. The second limitation is reliability of ultrasonography as a diagnostic tool for NAFLD. Diagnosis by ultrasonography has inevitable limitations due to low sensitivity for mild steatosis, inability to differentiate mild fibrosis from steatosis, and inaccurate quantification of fatty infiltration [62]. And more, interobserver and intraobserver variability in the sonographic assessment of fatty liver are well known [63]. Nevertheless, these shortcomings were thought to be minimal, because well-trained operators and gastroenterologists in a single hospital diagnosed fatty liver with prescribed findings written above in this study. In fact, we have already reported some study results based on our ultrasonography-based diagnoses $[31,64]$. The third limitation is the diagnostic accuracy of H. pylori infection based on serology. Though urea breath test (UBT) is superior to the serology test, the serology test is used due to its non-invasiveness and cost-effectiveness in our medical check up, which routinely has blood drawing. The accuracy of serology test in diagnosing $H$. pylori infection in this study was acceptable, since our recent study using the same study population showed that $97.8 \%$ $(1,638$ of 1,674$)$ of the subjects with sero-positivity of $H$. pylori had chronic atrophic gastritis[49]. The fourth limitation is the small number of female participants. We inferred that undetected association between MS and FLD including NAFLD might be due to the small number of female subjects who met MS criteria.

For the future prospects, we will follow this cohort to reveal the long-term effect of various associated factors upon FLD and NAFLD, such as developing NASH, liver cirrhosis, hepatocellular carcinoma, and so on.

\section{Conclusions}

Body mass index (BMI), serum ALT, and platelet count were positively associated with the presence of fatty liver disease (FLD) and non-alcoholic fatty liver disease (NAFLD) in both genders. On the other hands, Helicobacter pylori infection was not associated with either FLD or NAFLD.

\section{Additional file}

Additional file 1: Table S1. Background characteristics of the included 18,654 subjects and the excluded 2,119 subjects.

\section{Abbreviations}

FLD: Fatty liver disease; NAFLD: Non-alcoholic fatty liver disease; AFLD: Alcoholic fatty liver disease; HCC: Hepatocellular carcinoma; $H$. pylori: Helicobacter pylori; BMl: Body mass index; AST: Aspartate aminotransferase; ALT: Alanine aminotransferase; GGT: Gamma-glutamyl transpeptidase; T-Bil: Total bilirubin; ALB: Albumin; PLT: Platelet; TC: Total cholesterol; HDL-C: High-density lipoprotein; LDL-C: Low-density lipoprotein cholesterol; TG: Triglyceride; FBS: Fasting blood sugar; SBP: Systolic blood pressure; DBP: Diastolic blood pressure; MS: Metabolic syndrome.

\section{Competing interests}

The authors declare that they have no competing interests.

\section{Authors' contributions}

$\mathrm{KO}, \mathrm{YT}$ and NY contributed to the study concept and design, acquisition of data, analysis and interpretation of data, statistical analysis, and drafting of the manuscript. TS participated in support of statistical analysis. EK, HF, $\Pi$, YS, SY, SO and SK participated in critical revision of the manuscript for important intellectual content, analysis and interpretation of data. MF, KM and $\mathrm{HY}$ critically revised the manuscript for important intellectual content. TM and KK participated in study concept and design and study supervision. 
We confirm that all authors checked and approved the final version of the manuscript.

\section{Acknowledgements}

We thank Mr. Minoru Okada and Mr. Masanori Fujiwara (Kameda Medical Center Makuhari) for maintaining the study database. We also thank Mr. Koichi Yamashita (Kameda Medical Center Makuhari) for useful advice about the diagnosis of ultrasonography-based fatty liver. This work was supported in part by Grant-in-Aid for Young Scientists (B) from the Ministry of Education, Culture, Sports, Science and Technology (MEXT); Health Sciences Research Grants of The Ministry of Health, Labour and Welfare of Japan (Research on Hepatitis); and a grant from the Smoking Research Foundation of Japan.

\section{Author details}

'Department of Gastroenterology, Graduate School of Medicine, The University of Tokyo, Tokyo, Japan. ${ }^{2}$ Kameda Medical Center Makuhari (CD-2, 1-3, Nakase, Mihama-ku, Chiba-city, Japan.

\section{Received: 19 January 2015 Accepted: 2 February 2015}

\section{Published online: 19 February 2015}

\section{Reference}

1. Volzke H. Multicausality in fatty liver disease: is there a rationale to distinguish between alcoholic and non-alcoholic origin? World J Gastroenterol. 2012:18(27):3492-501.

2. Bellentani S, Saccoccio G, Costa G, Tiribelli C, Manenti F, Sodde M, et al. Drinking habits as cofactors of risk for alcohol induced liver damage. The Dionysos Study Group. Gut. 1997;41(6):845-50.

3. Bellentani S, Bedogni G, Miglioli L, Tiribelli C. The epidemiology of fatty liver. Eur J Gastroenterol Hepatol. 2004;16(11):1087-93.

4. DoS Alves De Carvalho M, Coelho Cabral P, Kruze Grande De Arruda I, Goretti Pessoa De Araujo Burgos M, Da Silva Diniz A, Barros Pernambuco JR, et al. Risk factors associated with hepatic steatosis: a study in patients in the Northeast Brazil. Nutr Hosp. 2012;27(4):1344-50.

5. Bellentani S, Saccoccio G, Masutti F, Croce LS, Brandi G, Sasso F, et al. Prevalence of and risk factors for hepatic steatosis in Northern Italy. Ann Intern Med. 2000;132(2):112-7.

6. Lau K, Lorbeer R, Haring R, Schmidt CO, Wallaschofski H, Nauck M, et al. The association between fatty liver disease and blood pressure in a population-based prospective longitudinal study. J Hypertens. 2010;28(9):1829-35.

7. Chalasani N, Younossi Z, Lavine JE, Diehl AM, Brunt EM, Cusi K, et al. The diagnosis and management of non-alcoholic fatty liver disease: practice Guideline by the American Association for the Study of Liver Diseases, American College of Gastroenterology, and the American Gastroenterological Association. Hepatol (Baltimore, Md). 2012;55(6):2005-23.

8. Sookoian S, Castano GO, Pirola CJ. Modest alcohol consumption decreases the risk of non-alcoholic fatty liver disease: a meta-analysis of 43175 individuals. Gut. 2014;63(3):530-2.

9. Hamaguchi M, Kojima T, Ohbora A, Takeda N, Fukui M, Kato T. Protective effect of alcohol consumption for fatty liver but not metabolic syndrome. World J Gastroenterol. 2012;18(2):156-67.

10. Liangpunsakul S, Chalasani N. What should we recommend to our patients with NAFLD regarding alcohol use? Am J Gastroenterol. 2012;107(7):976-8.

11. Kojima S, Watanabe N, Numata M, Ogawa T, Matsuzaki S. Increase in the prevalence of fatty liver in Japan over the past 12 years: analysis of clinical background. J Gastroenterol. 2003;38(10):954-61.

12. Ryan CK, Johnson LA, Germin BI, Marcos A. One hundred consecutive hepatic biopsies in the workup of living donors for right lobe liver transplantation. Liver Transpl. 2002;8(12):1114-22.

13. Nadalin S, Malago M, Valentin-Gamazo C, Testa G, Baba HA, Liu C, et al. Preoperative donor liver biopsy for adult living donor liver transplantation: risks and benefits. Liver Transpl. 2005;11(8):980-6.

14. Tran TT, Changsri C, Shackleton CR, Poordad FF, Nissen NN, Colquhoun S, et al. Living donor liver transplantation: histological abnormalities found on liver biopsies of apparently healthy potential donors. J Gastroenterol Hepatol. 2006;21 (2):381-3.

15. Lee JY, Kim KM, Lee SG, Yu E, Lim YS, Lee HC, et al. Prevalence and risk factors of non-alcoholic fatty liver disease in potential living liver donors in Korea: a review of 589 consecutive liver biopsies in a single center. J Hepatol. 2007;47(2):239-44.
16. Minervini MI, Ruppert K, Fontes P, Volpes R, Vizzini G, de Vera ME, et al. Liver biopsy findings from healthy potential living liver donors: reasons for disqualification, silent diseases and correlation with liver injury tests. J Hepatol. 2009;50(3):501-10.

17. Vernon G, Baranova A, Younossi ZM. Systematic review: the epidemiology and natural history of non-alcoholic fatty liver disease and non-alcoholic steatohepatitis in adults. Aliment Pharmacol Ther. 2011;34(3):274-85.

18. Baffy G, Brunt EM, Caldwell SH. Hepatocellular carcinoma in non-alcoholic fatty liver disease: an emerging menace. In: Journal of hepatology. Volume 56. England: Published by Elsevier B.V; 2012. p. 1384-91.

19. Rubinstein E, Lavine JE, Schwimmer JB. Hepatic, cardiovascular, and endocrine outcomes of the histological subphenotypes of nonalcoholic fatty liver disease. Semin Liver Dis. 2008;28(4):380-5.

20. de Alwis NM, Day CP. Non-alcoholic fatty liver disease: the mist gradually clears. J Hepatol. 2008:48 Suppl 1:S104-12.

21. Machado M, Marques-Vidal P, Cortez-Pinto H. Hepatic histology in obese patients undergoing bariatric surgery. J Hepatol. 2006;45(4):600-6.

22. Targher G, Bertolini L, Padovani R, Rodella S, Tessari R, Zenari L, et al. Prevalence of nonalcoholic fatty liver disease and its association with cardiovascular disease among type 2 diabetic patients. Diabetes Care. 2007:30(5):1212-8.

23. Marchesini G, Bugianesi E, Forlani G, Cerrelli F, Lenzi M, Manini R, et al. Nonalcoholic fatty liver, steatohepatitis, and the metabolic syndrome. Hepatology. 2003;37(4):917-23.

24. Frasinariu OE, Ceccarelli S, Alisi A, Moraru E, Nobili V. Gut-liver axis and fibrosis in nonalcoholic fatty liver disease: an input for novel therapies. Dig Liver Dis. 2013:45(7):543-51.

25. Henao-Mejia J, Elinav E, Jin C, Hao L, Mehal WZ, Strowig T, et al. Inflammasome-mediated dysbiosis regulates progression of NAFLD and obesity. Nature. 2012;482(7384):179-85.

26. Solga SF, Diehl AM. Gut flora-based therapy in liver disease? The liver cares about the gut. Hepatology (Baltimore, Md). 2004;39(5):1197-200.

27. Chassaing B, Etienne-Mesmin L, Gewirtz AT. Microbiota-liver axis in hepatic disease. Hepatology (Baltimore, Md). 2014;59(1):328-39.

28. Cover TL, Blaser MJ. Helicobacter pylori in health and disease. Gastroenterology. 2009;136(6):1863-73.

29. Malfertheiner P, Megraud F, O'Morain CA, Atherton J, Axon AT, Bazzoli F, et al. Management of Helicobacter pylori infection-the Maastricht IV/ Florence Consensus Report. Gut. 2012;61(5):646-64.

30. Matsuhisa T, Aftab H. Observation of gastric mucosa in Bangladesh, the country with the lowest incidence of gastric cancer, and Japan, the country with the highest incidence. Helicobacter. 2012;17(5):396-401.

31. Takahashi Y, Yamamichi N, Shimamoto T, Mochizuki S, Fujishiro M, Takeuchi $C$, et al. Helicobacter pylori infection is positively associated with gallstones: a large-scale cross-sectional study in Japan. J Gastroenterol. 2014;49(5):882-9

32. Patel P, Mendall MA, Carrington D, Strachan DP, Leatham E, Molineaux N, et al. Association of Helicobacter pylori and Chlamydia pneumoniae infections with coronary heart disease and cardiovascular risk factors. BMJ. 1995;311(7007):711-4.

33. Federman DG, Kirsner RS, Moriarty JP, Concato J. The effect of antibiotic therapy for patients infected with Helicobacter pylori who have chronic urticaria. J Am Acad Dermatol. 2003;49(5):861-4.

34. Maurer KJ, Ihrig MM, Rogers AB, Ng V, Bouchard G, Leonard MR, et al. Identification of cholelithogenic enterohepatic helicobacter species and their role in murine cholesterol gallstone formation. Gastroenterology. 2005;128(4):1023-33.

35. Naja F, Nasreddine L, Hwalla N, Moghames P, Shoaib H, Fatfat M, et al. Association of $\mathrm{H}$. pylori infection with insulin resistance and metabolic syndrome among Lebanese adults. Helicobacter. 2012;17(6):444-51.

36. Cho I, Blaser MJ, Francois F, Mathew JP, Ye XY, Goldberg JD, Bini EJ: Helicobacter pylori and overweight status in the United States: data from the Third National Health and Nutrition Examination Survey. In: Am J Epidemiol. Volume 162, edn. United States; 2005: 579-584.

37. Longo-Mbenza B, Nkondi Nsenga J, Vangu Ngoma D. Prevention of the metabolic syndrome insulin resistance and the atherosclerotic diseases in Africans infected by Helicobacter pylori infection and treated by antibiotics. Int J Cardiol. 2007;121(3):229-38.

38. Polyzos SA, Kountouras J, Zavos C, Deretzi G. Helicobacter pylori Infection and insulin resistance. Helicobacter. 2013;18(2):165-6. 
39. Stergiopoulos C, Kountouras J, Daskalopoulou-Vlachoyianni E, Polyzos SA,

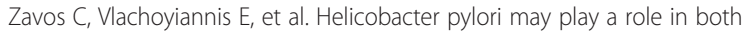
obstructive sleep apnea and metabolic syndrome. Sleep Med. 2012;13 (2):212-3.

40. Shin DW, Kwon HT, Kang JM, Park JH, Choi HC, Park MS, et al. Association between metabolic syndrome and Helicobacter pylori infection diagnosed by histologic status and serological status. J Clin Gastroenterol. 2012;46 (10):840-5.

41. Pietroiusti A, Diomedi M, Silvestrini M, Cupini LM, Luzzi I, Gomez-Miguel MJ, et al. Cytotoxin-associated gene-A-positive Helicobacter pylori strains are associated with atherosclerotic stroke. Circulation. 2002;106(5):580-4.

42. Gunji T, Matsuhashi N, Sato H, Fujibayashi K, Okumura M, Sasabe N, et al. Helicobacter pylori infection is significantly associated with metabolic syndrome in the Japanese population. Am J Gastroenterol. 2008;103(12):3005-10.

43. Polyzos SA, Kountouras J, Papatheodorou A, Patsiaoura K, Katsiki E,

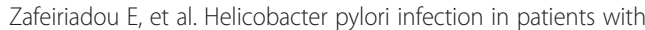
nonalcoholic fatty liver disease. Metabolism. 2013;62(1):121-6.

44. Danjo A, Yamaguchi K, Fujimoto K, Saitoh T, Inamori M, Ando T, et al. Comparison of endoscopic findings with symptom assessment systems (FSSG and QUEST) for gastroesophageal reflux disease in Japanese centres. J Gastroenterol Hepatol. 2009;24(4):633-8.

45. Kusano M, Shimoyama Y, Sugimoto S, Kawamura O, Maeda M, Minashi K, et al. Development and evaluation of FSSG: frequency scale for the symptoms of GERD. J Gastroenterol. 2004;39(9):888-91.

46. Yamamichi N, Mochizuki S, Asada-Hirayama I, Mikami-Matsuda R, Shimamoto T, Konno-Shimizu M, et al. Lifestyle factors affecting gastroesophageal reflux disease symptoms: a cross-sectional study of healthy 19864 adults using FSSG scores. BMC Med. 2012;10:45.

47. Shimamoto T, Yamamichi N, Kodashima S, Takahashi Y, Fujishiro M, Oka M, et al. No association of coffee consumption with gastric ulcer, duodenal ulcer, reflux esophagitis, and non-erosive reflux disease: a cross-sectional study of 8,013 healthy subjects in Japan. PLoS One. 2013;8(6):e65996.

48. Minatsuki C, Yamamichi N, Shimamoto T, Kakimoto H, Takahashi Y, Fujishiro M, et al. Background factors of reflux esophagitis and non-erosive reflux disease: a cross-sectional study of 10,837 subjects in Japan. PLoS One. 2013;8(7):e69891.

49. Yamamichi N, Hirano C, Shimamoto T, Minatsuki C, Takahashi Y, Nakayama C, et al. Associated factors of atrophic gastritis diagnosed by double-contrast upper gastrointestinal barium x-ray radiography: a cross-sectional study analyzing 6,901 healthy subjects in Japan. PLoS One. 2014;9(10):e111359.

50. Hamaguchi M, Kojima T, Itoh Y, Harano Y, Fujii K, Nakajima T, et al. The severity of ultrasonographic findings in nonalcoholic fatty liver disease reflects the metabolic syndrome and visceral fat accumulation. Am J Gastroenterol. 2007;102(12):2708-15.

51. [Definition and the diagnostic standard for metabolic syndrome-Committee to Evaluate Diagnostic Standards for Metabolic Syndrome]. Nihon Naika Gakkai zasshi The Journal of the Japanese Society of Internal Medicine 2005, 94(4):794-809.

52. Karcz WK, Krawczykowski D, Kuesters S, Marjanovic G, Kulemann B, Grobe H, et al. Influence of Sleeve Gastrectomy on NASH and Type 2 Diabetes Mellitus. J Obes. 2011;2011:765473.

53. Dowman JK, Tomlinson JW, Newsome PN. Systematic review: the diagnosis and staging of non-alcoholic fatty liver disease and non-alcoholic steatohepatitis. Aliment Pharmacol Ther. 2011;33(5):525-40.

54. Inabe F, Takahashi E, Moriyama K, Negami M, Otsuka H. Risk assessment chart for predicting fatty liver in Japanese subjects. Tokai J Exp Clin Med. 2012;37(4):94-101.

55. Becker U, Deis A, Sorensen Tl, Gronbaek M, Borch-Johnsen K, Muller CF, et al. Prediction of risk of liver disease by alcohol intake, sex, and age: a prospective population study. Hepatology. 1996;23(5):1025-9.

56. Ludwig J, McGill DB, Lindor KD. Review: nonalcoholic steatohepatitis. J Gastroenterol Hepatol. 1997;12(5):398-403.

57. Lucey MR, Mathurin P, Morgan TR. Alcoholic hepatitis. N Engl J Med. 2009;360(26):2758-69.

58. Altamirano J, Bataller R. Alcoholic liver disease: pathogenesis and new targets for therapy. Nat Rev Gastroenterol Hepatol. 2011;8(9):491-501.

59. Mulhall BP, Ong JP, Younossi ZM. Non-alcoholic fatty liver disease: an overview. J Gastroenterol Hepatol. 2002;17(11):1136-43.

60. Sheth SG, Gordon FD, Chopra S. Nonalcoholic steatohepatitis. Ann Intern Med. 1997;126(2):137-45.
61. Bugianesi E, Leone N, Vanni E, Marchesini G, Brunello F, Carucci P, et al. Expanding the natural history of nonalcoholic steatohepatitis: from cryptogenic cirrhosis to hepatocellular carcinoma. Gastroenterology. 2002:123(1):134-40.

62. Festi $D$, Schiumerini $R$, Marzi L, Di Biase AR, Mandolesi D, Montrone L, et al. Review article: the diagnosis of non-alcoholic fatty liver disease - availability and accuracy of non-invasive methods. Aliment Pharmacol Ther 2013;37(4):392-400.

63. Strauss S, Gavish E, Gottlieb P, Katsnelson L. Interobserver and intraobserver variability in the sonographic assessment of fatty liver. AJR Am J Roentgenol. 2007;189(6):W320-3.

64. Yamaji Y, Okamoto M, Yoshida H, Kawabe T, Wada R, Mitsushima T, et al Cholelithiasis is a risk factor for colorectal adenoma. Am J Gastroenterol. 2008;103(11):2847-52.

\section{Submit your next manuscript to BioMed Central and take full advantage of:}

- Convenient online submission

- Thorough peer review

- No space constraints or color figure charges

- Immediate publication on acceptance

- Inclusion in PubMed, CAS, Scopus and Google Scholar

- Research which is freely available for redistribution 